\title{
Can Game-based Learning Facilitate Civics, Negotiation and Conflict Management Attributes? Research Evidence from Greek University Students
}

\author{
Eleni Makri \\ Insight SFI Research Centre for Data Analytics/UCD, Research Scientist, Dublin, Ireland
}

In loving memory of my parents, Doctor Georgios Makris, teacher Georgia Tsiotou-Makri and my friend Poirot

\begin{abstract}
Games for captivating education and training experience bear an increasingly significant shared issue for lecturers and game developers multiculturally. Endorsing no axioms for successful civics, negotiation and sustainability game-based learning and competence decisions, this study relies on exploring negotiation/conflict resolution and civics/sustainability-associated attributes investigated in game-based learning university context. We describe 60 Greek private university students' negotiation/conflict resolution and civics/sustainability management-related knowledge, attitudes and skills post-gameplay when set side by side with lecture instruction as part of negotiation module in organizational behaviour course sessions in academic years 2019/2020. Our empirical evidence indicates that game-based negotiation/conflict resolution and civics/sustainability learning facilitates conflict and civics/sustainability utilitarian decisionmaking in relation to analogous lecture attributes. The game-based negotiation/conflict resolution and civics/sustainability continuum favourable outcomes gained are discussed in light of theoretical and practical implications and avenues for further research in tandem with universal game-based negotiation/conflict resolution and civics/sustainability management-related education, pedagogy and practice.
\end{abstract}

\section{Introduction}

Educational (serious games) by adopting purpose (edutainment), reality (set up in artificially driven real world environment), social interaction and social presence (from single player to massive multiplayer online ones) and player activity (active player with AR/VR game elements or more static player situation) have been related to favourable student knowledge, attitudes and skills. They could foster social interaction attributes by integrating metacognitive strategies into gameplay, leading to better academic record and learning engagement and facilitate writing capacity via thinking aloud and modeling in the gameplay [1]. Facilitating communicative skills like collaboration and (or) reflection, analytical, spatial, strategic skills and insight, learning and recollection capacity, psychomotor skills, visual selective attention and improved self-monitoring, greater short-and-longterm memory, and higher levels of social skills [2]. Also in cases of students designing games gaining not only scientific concept gaming, but also improved digital agency and engagement in the design process [3]. Vogel et al. [4] in their meta-analysis evaluating various studies concerning games and interactive simulations against traditional classroom teaching, indicate that application of games or simulations ended up in significantly increased cognitive benefits and improved attitudes towards learning than with the use of traditional classroom teaching. Evidence of assessment on serious games and lecture instruction tends not to have arrived at either an axiomatic framework of their learning performance across different learner cohorts nor secure relationships between negotiation/conflict resolution and civics/sustainability continuum attributes when examined in university practice, in specific [5]. Along this vein, therefore, exploring negotiation/conflict management and civics agency and sustainability evaluation to learning experience via serious gaming across postgraduate students as near to labour force, might reveal further the learning knowledge, attitudes and skills that serious games might bring as increasing yet still rather not extensive instructional tools for negotiation/conflict resolution and civics/sustainability-related learning in university domain, as described below.

In this setting, the current paper aims to report on the findings of a study conducted as part of class sessions in negotiation module within organizational 
behaviour curriculum at a private university in Greece. Exploring lecture and gameplay student negotiation/conflict resolution and civics/sustainability-related knowledge, attitudes and skills in terms of self-confidence, cooperation, communication, compromise (bargaining), conflict resolution and civic action, interpersonal and problem-solving skills, political awareness, social justice, civic responsibility, seeking knowledge about political/societal issues and gains in problem-solving and leadership skills, in student-centered experiential lab sessions run during the academic years 20192020. The study was performed in 60 postgraduate students to explore the nature and range of their learning outcomes post-lecture and post-gameplay for negotiation/conflict management and civics/sustainability-related continuum as modes to facilitate effective negotiation/conflict resolution and civics/sustainability management through serious gaming and vice versa. Building on the aforementioned rationale, therefore, the research questions that correspond to the scope of the present study are the following:

- Are there significant relationships between negotiation/conflict resolution and civics/sustainability-associated knowledge, attitudes and skills variables post-gameplay?

- Are there any differences in the perceptions of negotiation/conflict management and civics/sustainability-related knowledge, attitudes and skills exercised by postgraduate students according to district origin and voting/non-voting in elections behaviour post-gameplay?

The remainder of the present paper is divided as follows. Section 2 illustrates a review about negotiation/conflict management and civics/sustainability-related research across lecture and serious games instruction in university education inter-culturally. Section 3 illustrates the study methodology, a brief description of the game employed and the empirical findings' analysis. Section 4 synopsizes the results, their implications regarding negotiation/conflict management and civics/sustainability-related paradigm and finishes this paper with future research on serious games exploration as open innovation tools in negotiation/conflict resolution and civics/sustainability-associated teaching and learning pedagogy and practice.

\section{Literature review}

Solinska-Nowakb et al. [6] report on their analysis of 45 disaster and risk management-associated serious games and simulations including 13 ones for college and university students, encompassing most kinds of environmental/natural risks/hazards (i.e. earthquakes, floods, wildfires, etc.). Targeted at advancing student sustainability awareness, emergency preparedness, active engagement in the incident of crises, effective decision making, spatial thinking, triggering public discussion about successful city management in the face of natural hazards, team-and-community building at local and international level, collaboration, interpersonal communication and cultural training, empathy, resilience, knowledge and information transfer to expert policy-makers. Pending on diverse game type and assessment method focus publications, the authors claim for no secure conclusions drawn. However, the positive learning outcomes gained included playability, reliability of disaster-related information provision and increasing awareness about flood risk and prevention provided embedding land management and local/community activities, positive effect in performing tasks outside the game context, facilitating humanitarian and civic-related assistance adopting multimodal perspective-taking and prioritizing corresponding activities, among others. Constantinescu, Devisch and Huybrechts [7] review 3 serious games as possible tools for reflecting on and fostering civic learning and intervention-orientation for community common good through engagement in public decision making and establishment of public procedures. The games were assessed according to the extent they tend to sustain a discussion between players (individuals) and gaming context (institutions) to identify, comment, share and act upon enduring social challenges, adopting thus the role of civic-life agents. The one related to risk abandonment challenge was used by adults in urban space festival location and seemed to motivate players and deemed helpful in exercising a sustainable city. The other one being a joint project by TU Delft and various stakeholders and a multiplayer spatial planning game aimed at practicing effective transit-oriented development (TOD) in the Dutch metropolitan district. The players had to create a plan for the spatial development of urban stations areas on a rail corridor and to implement it in compliance with the "norms" set by the players at the start of the game (e.g. public transport use, etc.) [8]. The designed prototype included 6 available roles reflecting the 6 cities on the Leiden-Schipol rail corridor. Each role or city location is played by at least one player or a team of players. The latter is divided pre-game beginning by a game leader. Game player scores are assessed against game player "norms" configured at the beginning of the game. Approximately 70 stakeholders across diverse institutions engaged in gameplay. 45 players indicated their perceptions regarding their gameplay learning practice and playability. It seemed that the game fostered a better comprehension of rail mobility and spatial development interaction with the urban stations location by stressing land use management to various stakeholder cohorts in a trial and error 
artificial way environment not bearing critical direct consequences as might happen in real life. The last one was employed to instigate public dialogue about community needs challenges, as well. Providing a virtual reality experiential space for open innovation, the games tend to exercise collective efficacy in play. Participants seem to become active makers of their city space by playful engaging in the co-creation process of their urban stations location environment. Game designer Tad Hirsch claims that the process of civic action is more significant rather than its scores, thus the aim of these games should be to foster evolving and endurable participation in civic life [9 $\mathrm{p}$ 342]. The three games indicated a range of principles that can be employed to assist spatial capacity agency - from brief civic activities powered by a serious game, to a more profound engagement in local challenges through face-to-face planning game. In both circumstances, though, with evident clear regulations, targets and a motivational game structure for immersive and interactive learning player participation. Peng and her colleagues [10] in their study about Darfur is Dying indicate that players disposition towards helping others in need and assume role-taking perspective improved post-gameplay in comparison to text and video outcomes about the same challenge (i.e. the famine situation in Darfur). Raessens [11] analyzing Darfur is Dying and Food Force, suggests that the gameplay practice of assuming the role of "co-creator ends up in a powerful discursive space and experience, with real enough power to affect the terms in which people think, feel and act" (p. 258). This becomes evident also in [12] research on Poverty Is Not a Game. Developed by the EU in reference to the European year against poverty and social exclusion, the game targets at instigating knowledge, attitudes and skills associated with the above open challenges among young and mature students, in particular. Scoring on civic-related KASs immediately post-gameplay was higher in relation to that assessed 3 months after gameplay. One third of the participants reported that they had been more civic-oriented post-3 months gameplay. It was this same cohort that indicated mostly discussing with their family members about poverty issue. It appears, therefore, that gameplay experience seemed to act as triggering effect, while discussing about the challenge might have fostered a change in attitude about whether or not participants tend to identify themselves as civic-interested. Ruggiero [13] indicates a sleeper effect in her longitudinal study among players of Spent. The game reflects awareness about homelessness. Evidence indicates that the game did not seem to have an impact immediately postgameplay, but when participants were assessed 3 weeks later, they demonstrated more positive knowledge, attitudes and skills towards homelessness in relation to their peers who did not experience this gameplay. This finding tends to indicate the rather transformative learning effect of serious games in comparison to more traditional classroom instruction evidenced in other circumstances, too [14]. Glass et al [15] point to the increasing nature of relevant academic research on game mechanics and pedagogy and equally the ongoing need to investigate the longterm effects of gameplay experience on civic real life attitudes, further. Kahne et al. [16] found a positive relationship between engagement/civics games and their corresponding levels of civic opinion expression and political activity. Gordon et al. [17] point to CommunityPlanit, a serious game aimed at favourably affecting civic engagement, developed and assessed for local planning. Through this gameplay, participants are firstly educated on challenges linked to their communities, then asked to share and discuss the issues with each other, propose solutions and vote in favour of the solutions they most relate to, so that the solutions might be funded by the government budget. This game is reported to be used in the city of Detroit, USA and in the republic of Moldova with great success.

\section{Research Methodology}

The following section describes the study design employed, a brief description of the game used and the empirical findings' analysis performed, as indicated next.

\subsection{Study design}

60 private university students (36 male, 24 female, 32 from Attica, 28 from other district origin) registered in work and organizational psychology courses were randomly selected [18] to participate in the present study as part of their three hour lab session on negotiation module. Post-informed consent provided, they were first required to complete demographic information concerning gender, residency, age range, working status (public vs private) and registration to vote in elections questions. Afterwards, they attended an hour of negotiation/sustainability lecture (including completion of corresponding assigned tasks). Next, they answered a) the negotiation/conflict resolution continuum items obtained by the Five Factor Negotiation Scale (FFNS) [19] and b) the Civic Attitudes and Skills Questionnaire (CASQ) reflecting civic/sustainability issues [20]. The first instrument tool addressed the following scales: a) self-confidence (i.e. measuring the students' confidence in their self necessary to being an assertive negotiator), b) cooperation (i.e. assessing participants' willingness to cooperate or work together with others), c) communication (i.e. evaluating respondents' willingness to cooperate or work together with other people), d) compromise/bargaining (i.e. measuring students' disposition to give something up, make 
exchanges and address others' needs in order to accomplish their targets), with all of them having a 5point Likert type answering format pending on how often the particular statements apply to the respondents $(1=$ never to $5=$ always $)$ and e) conflict resolution/management (i.e. inclination to talk out to resolve a disagreement or problem rather than fighting in the face of conflict). This scale included 6 questions referring to the type of relationship involved (i.e. parents/guardian, teachers, friends, sisters/brothers, people of same age who are not friends, partner). For each of the above questions, students were presented with 5 answer choices, from which they were asked to rank their top 3 on how they deal with disagreements, problems and (or) conflicts (i.e. physical fight, argument, walk away, get an adult and talk it out). All FFN scales indicated moderate to high $a$ consistency reliabilities (i.e. 0.75 to 0.80 ) except self-confidence and communication scales that were not included in the analyses due to lower reliability.

The second instrument tool comprised of 10 scales (i.e. civic action, interpersonal and problem-solving skills, political awareness, leadership skills, social justice and diversity attitudes, seeks knowledge about political/societal issues, gains in problem-solving and leadership skills, civic responsibility). All items included 5-point Likert type questions pending on the extent of agreement or disagreement with each statement (1=completely disagree to $5=$ completely agree). All CASQ scales demonstrated moderate to high $a$ consistency reliabilities (i.e. 0.75 to 0.88 ), apart from diversity attitudes and leadership skills scales that were not included in the analyses due to decreased reliability. In both tools, questions that were negatively worded for presentation were reverse coded before analyses were executed. Students completed their negotiation/conflict management attitudes and skills and civics/sustainability questionnaires based on their overall experience with the negotiation lecture introduced (post-lecture). The second and third hour of their lab session the lecturer first introduced them to a civics/sustainability educational game through a demo. Students were encouraged and instructed to play the game as long as they pleased either individually or in pairs across all game levels and actions for up to one hour. Observations, video recordings and debriefing of the participants indicated that the majority of them were engaged in their gameplay sessions and completed all required game tasks. Following [21], the lecturer acted also as mediator and prompted positive discourse subsequent to the game, encouraging students to participate in interactive discussions leading to reflection post-gaming. After gameplay, they were required to complete the same negotiation/conflict and civics/sustainability-related attitudes and skills questionnaire as after lecture (postgameplay).

\subsection{Description of the game}

International organizations such as Games for Change (G4C) have contributed to advanced interest in designing games that tend to exercise social and civics/sustainability knowledge, attitudes and skills among player communities. In "Cards Against Calamity" (CACG) educational game (created by 1 st Playable Productions and support from the Environmental Law Institute, the NOAA and the Wilson Center as a pedagogical tool for educators with Figure 1 below indicating a sample screenshot of the game), you assume the role of a mayor of a small coastal town. You have to counterbalance the objectives and needs of diverse stakeholders, from fishermen to tourists and SMEs owners whilst securing the town from job losses, environmental hazards, natural disasters like hurricanes and trendy young visitors.

The first main challenge is decision-making: You select between regions of the United States, each with its own community events and choices. Will you decide to bring more tourists or train new fishermen? Will you invest your funding in emergency services improvement or in road repairing? Encouraged to weigh up the individual or community needs of your constituency members? In doing so, you are given positive and negative feedback from your community groups via social media feeds. The second main challenge is building resilience: You need to proactively manage events and be prepared for the future to ensure your town is ready. You have to guide your community members to help together those in most need in weather crises and disaster incidents, so all appear adrift.

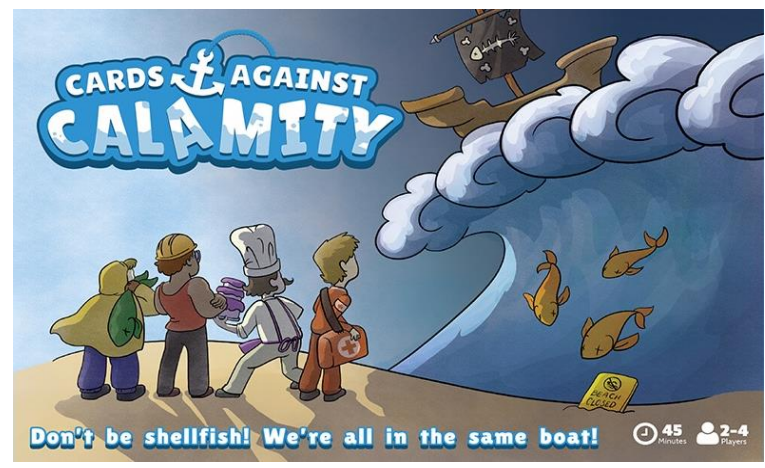

Figure 1. Screenshot of CACG

\subsection{Data analysis and results}

36 male and 24 female students $(\mathrm{N}=60)$ from Attica $(\mathrm{N}=32)$ and non Attica $(\mathrm{N}=28)$ district origin provided completed negotiation/conflict management and civics/sustainability-related instruments overall post-lecture and post-gameplay, respectively. 
Table 1. Means (M), standard deviations (SD), intercorrelations and coefficient alphas of the study variables post-gameplay $(\mathrm{N}=60)$

\begin{tabular}{l|c|c|c|c|c|c|c|c|c|c|c|c|c|c|c|c}
\hline & $\mathrm{M}$ & $\mathrm{SD}$ & 1 & 2 & 3 & 4 & 5 & 6 & 7 & 8 & 9 & 10 & 11 & 12 & 13 & 14 \\
\hline $\mathrm{C}$ & 3.22 & .48 & $(0.75)$ & & & & & & & & & & & & \\
\hline $\mathrm{CB}$ & 3.14 & .56 & $.34^{* *}$ & $(0.76)$ & & & & & & & & & & & \\
\hline $\mathrm{VF}$ & 1.29 & .47 & $-.22 \mathrm{~ns}$ & $-.08 \mathrm{~ns}$ & $(0.75)$ & & & & & & & & & & & \\
\hline $\mathrm{N}$ & 1.93 & 1.05 & $.38^{* *}$ & $-.01 \mathrm{~ns}$ & $-.15 \mathrm{~ns}$ & $(0.79)$ & & & & & & & & & & \\
\hline GA & 0.69 & .81 & $.12 \mathrm{~ns}$ & $-.10 \mathrm{~ns}$ & $-.55^{* *}$ & $.42^{* *}$ & $(0.80)$ & & & & & & & & & \\
\hline $\mathrm{N}$ & 1.15 & .47 & $-.13 \mathrm{~ns}$ & $.06 \mathrm{~ns}$ & $-.25^{*}$ & $-.50^{* *}$ & $-.17 \mathrm{~ns}$ & $(0.77)$ & & & & & & & & \\
\hline $\mathrm{CA}$ & 3.38 & .69 & $.13 \mathrm{~ns}$ & $-.09 \mathrm{~ns}$ & $-.00 \mathrm{~ns}$ & $-.03 \mathrm{~ns}$ & $-.08 \mathrm{~ns}$ & $.14 \mathrm{~ns}$ & $(0.84)$ & & & & & & & \\
\hline IPS & 3.94 & .64 & $.07 \mathrm{~ns}$ & $.05 \mathrm{~ns}$ & $-.16 \mathrm{~ns}$ & $-.10 \mathrm{~ns}$ & $-.00 \mathrm{~ns}$ & $.10 \mathrm{~ns}$ & $.53^{* *}$ & $(0.88)$ & & & & & & \\
\hline PA & 3.83 & .87 & $.04 \mathrm{~ns}$ & $-.01 \mathrm{~ns}$ & $.10 \mathrm{~ns}$ & $.01 \mathrm{~ns}$ & $.11 \mathrm{~ns}$ & $.00 \mathrm{~ns}$ & $.46^{* *}$ & $.52^{* *}$ & $(0.79)$ & & & & & \\
\hline SJ & 3.71 & .40 & $.13 \mathrm{~ns}$ & $-.02 \mathrm{~ns}$ & $-.05 \mathrm{~ns}$ & $.03 \mathrm{~ns}$ & $.15 \mathrm{~ns}$ & $.01 \mathrm{~ns}$ & $.21 \mathrm{~ns}$ & $.30^{*}$ & $.45^{* *}$ & $(0.75)$ & & & & \\
\hline CR & 3.53 & .63 & $.36^{* *}$ & $.00 \mathrm{~ns}$ & $.09 \mathrm{~ns}$ & $.03 \mathrm{~ns}$ & $-.11 \mathrm{~ns}$ & $.10 \mathrm{~ns}$ & $.52^{* *}$ & $.47^{* *}$ & $.57^{* *}$ & $.42^{* *}$ & $(0.83)$ & & & \\
\hline SK & 3.39 & .65 & $.19 \mathrm{~ns}$ & $-.09 \mathrm{~ns}$ & $-.16 \mathrm{~ns}$ & $.10 \mathrm{~ns}$ & $.13 \mathrm{~ns}$ & $.12 \mathrm{~ns}$ & $.28^{*}$ & $.47^{* *}$ & $.54^{* *}$ & $.43^{* *}$ & $.49^{* *}$ & $(0.75)$ & & \\
\hline GP & 4.07 & .91 & $.26 \mathrm{~ns}$ & $.86 \mathrm{~ns}$ & $.46 \mathrm{~ns}$ & $.97 \mathrm{~ns}$ & $.41 \mathrm{~ns}$ & $.51 \mathrm{~ns}$ & $.00 \mathrm{~ns}$ & $.00 \mathrm{~ns}$ & $.00 \mathrm{~ns}$ & $.02 \mathrm{~ns}$ & $.00 \mathrm{~ns}$ & $.01 \mathrm{~ns}$ & $(0.82)$ & \\
\hline GL & 3.52 & .84 & $.03 \mathrm{~ns}$ & $-.08 \mathrm{~ns}$ & $-.01 \mathrm{~ns}$ & $-.13 \mathrm{~ns}$ & $-.15 \mathrm{~ns}$ & $.16 \mathrm{~ns}$ & $.47^{* *}$ & $.50^{* *}$ & $.28^{*}$ & $.29^{*}$ & $.58^{* *}$ & $.24 \mathrm{~ns}$ & $.74^{* *}$ & $(0.76)$ \\
\hline
\end{tabular}

$a$ coefficients are illustrated on the diagonal; * $\mathrm{p}<.05 ; * * \mathrm{p}<.01$ (2-tailed)

Table 1 presents the bivariate Pearson's $r$ correlations between all study negotiation/conflict management and civics/sustainability-associated variables/scales post-gameplay, accordingly. To assess potential differences in negotiation/conflict resolution and civics/sustainability-related attributes exhibited by the respondents post-gameplay, a 2 (district: Attica vs non Attica) x 2 (voting in elections: yes vs no) between groups ANOVAs were performed, as indicated in Tables 2 and 3 that follow next.

Correlations: Table 1 above illustrates the means (M), standard deviations (SD), intercorrelations and $a$ consistency reliability for all study variables employed post-gameplay. At the bivariate level and corresponding to the negotiation/conflict resolution variables post-gameplay, cooperation correlated significantly positively with compromise/bargaining $(\mathrm{r}=0.34)$, "walk away" (neutral) $(\mathrm{r}=0.38)$ and civic responsibility $(\mathrm{r}=0.36)$, get an adult significantly negatively with verbal fight $(\mathrm{r}=-0.55)$ and positively with neutral $(\mathrm{r}=0.42)$, walk away significantly negatively with verbal fight and neutral $(\mathrm{r}=-0.50)$. Interpersonal and problem-solving skills significantly positively with "get an adult" (constructive action) $(\mathrm{r}=0.53)$, political awareness with "get an adult" (constructive action) ( $\mathrm{r}=0.46)$ and interpersonal and problem-solving skills $(\mathrm{r}=0.52)$, social justice with interpersonal and problem-solving skills $(\mathrm{r}=0.30)$ and political awareness $(r=0.45)$, civic responsibility significantly positively with "get an adult" constructive action ( $\mathrm{r}=0.52)$, interpersonal and problem-solving skills $(\mathrm{r}=0.47)$, political awareness $(\mathrm{r}=0.57)$ and social justice $(\mathrm{r}=0.42)$, seeking knowledge about political/societal issues significantly positively with constructive action $(\mathrm{r}=0.28)$, interpersonal and problem-solving skills $(\mathrm{r}=0.47)$, political awareness $(r=0.54)$, social justice $(r=0.43)$ and civic responsibility $(\mathrm{r}=0.49)$, gains in leadership skills significantly positively with constructive action $(\mathrm{r}=0.47)$, interpersonal and problem-solving skills $(\mathrm{r}=0.50)$, political awareness $(\mathrm{r}=0.28)$, social justice $(\mathrm{r}=0.29)$, civic responsibility $(\mathrm{r}=0.58)$ and gains in problem-solving skills $(\mathrm{r}=0.74)$. The latter being the strongest correlation and the weakest that of neutral and verbal fight $(\mathrm{r}=-0.25)$.

\section{X2 ANOVAs}

Table 2 presents the relevant descriptive statistics that correspond to students' responses to each one of the negotiation/conflict resolution and civics/sustainability continuum variables measured post-gameplay assessment by district origin (i.e. Attica, other) and voting in elections (i.e. yes, no), where Table 3 illustrates the main and interaction effects for district (i.e. Attica, other) and voting (yes, no) for each of the aforementioned negotiation/conflict management and civics/sustainability-related variables assessed after students' gameplay. Finally, Figures 1 and 2 illustrate 
the nature of the interaction effects indicated in terms of district/region and voting in elections for conflict resolution "argument" (verbal fight) and civic action scores post-gameplay.

Cooperation: There was a non-significant main effect of district on students' willingness to cooperate or work together, $F(1,60)=0.201, p=.656$, partial $\eta^{2}=.004$, which means that Attica and non Attica students scored similarly in their disposition to cooperate or work together $(M=3.27$ and $M=3.09$, respectively) (estimated marginal means). There was a non-significant main effect of voting on students' willingness towards working things out with their coworkers, $F(2,60)=0.231, p=.795$, partial $\eta^{2}=.008$, which means that voting and no voting university students did exhibit similar scores in their perceptions of cooperation and working together on group projects $(\mathrm{M}=3.22$ and $\mathrm{M}=3.25$, accordingly) (estimated marginal means). There was a non-significant interaction effect between district and voting on students' cooperation scores, $\mathrm{F}(1,60)=.034, \mathrm{p}=.855$, partial $\eta^{2}=.001$. This indicates that university private education students reflecting Attica and non Attica both voting and no voting peers were not affected differently in the perception of cooperation or working things out with others $(\mathrm{M}=3.27$ and $\mathrm{M}=3.18$ as well as $\mathrm{M}=3.21$ and $\mathrm{M}=3.25$, respectively) (normal means).

Compromise/Bargaining: There was a non-significant main effect of district on students' willingness to give something up, make exchanges and address each other's needs to achieve one's goals, $F(1,59)=1.093$, $\mathrm{p}=.301$, partial $\eta^{2}=.020$, which means that Attica and non Attica students scored similarly in their disposition to compromise/bargain $(\mathrm{M}=3.27$ and $\mathrm{M}=3.21$, respectively) (estimated marginal means). There was a non-significant main effect of voting on students' compromise/bargaining scores, $F(2,59)=$ $0.317, p=.730$, partial $\eta^{2}=.012$, which means that voting and no voting students scored similarly in their willingness to compromise/bargain $(\mathrm{M}=3.14$ and $\mathrm{M}=$ 3.20 , accordingly) (estimated marginal means). There was a non-significant interaction effect between district and voting on students' disposition to give something up, make exchanges and consider each other's needs to accomplish one's goals scores, $\mathrm{F}(1,59)=1.015, \mathrm{p}=.903$, partial $\eta^{2}=.000$. This indicates that Attica and non Attica students both voting and no voting ones were not affected differently in the perception of compromise/bargaining willingness $(\mathrm{M}=3.24$ and $\mathrm{M}=3.07$, as well as $\mathrm{M}=3.13$ and $\mathrm{M}=$ 3.15 , accordingly) (normal means).

Conflict resolution "argument" (verbal fight): There was a non-significant main effect of district on students' conflict resolution "argument" (verbal fight) attitude post-assessment, $\mathrm{F}(1,60)=2.789, \mathrm{p}=.101$, partial $\eta^{2}=.048$, which means that Attica and non Attica students scored similarly in their attitude towards verbal fight $(M=1.52$ and $M=1.35$, respectively) (estimated marginal means). There was a significant main effect of voting on students' conflict resolution "argument" (verbal fight) attitude scores, $\mathrm{F}(2,60)=2.417, \mathrm{p}<0.10$, partial $\eta^{2}=.081$, which means that students who did not vote in elections scored significantly higher in conflict resolution "argument" (verbal fight) perceptions $(\mathrm{M}=1.56) \quad$ (estimated marginal means) than their voting peers $(M=1.24)$ (estimated marginal means) post-gameplay. There was a significant interaction effect between district and voting on respondents' conflict resolution "argument" (verbal fight) scores, $F(1,60)=6.173$, $\mathrm{p}<0.05$, partial $\eta^{2}=.101$. This indicates that postgraduate university students originated from Attica and non Attica region and voting and nonvoting ones were influenced differently in their perceptions of conflict resolution "argument" (verbal fight) post-gaming. Specifically, the perceptions of conflict resolution "argument" (verbal fight) indicated by students registered as non-voting $(\mathrm{M}=1.42)$ (means) were significantly higher than those reported by the ones registered as voting ones $(\mathrm{M}=1.24)$ (means) $\left(\mathrm{x}^{2}(20)=64.086, \mathrm{p}<.05\right)$. However, perceptions of conflict resolution "argument" (verbal fight) were similar in Attica $(\mathrm{M}=1.28)$ (means) and non Attica $(\mathrm{M}=1.29)$ (means) students $\left(\mathrm{x}^{2}(10)=\right.$ $12.725 \mathrm{p}=.224 \mathrm{~ns}$ ). Figure 2 below demonstrates the nature of the interaction effect, indicating that nonvoting perceptions significantly affect conflict resolution "argument" (verbal fight) perceptions in Attica region students (non Attica ones appear unaffected).

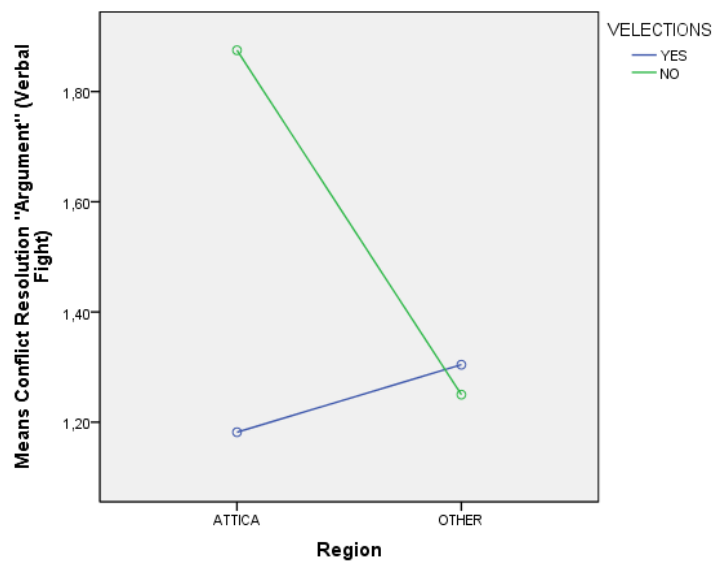

Figure 1. Graph of the interaction of district/region and voting in elections in verbal fight 
Table 2. Descriptive of university students' responses by district origin and voting in elections

\begin{tabular}{|c|c|c|c|c|}
\hline \multirow{2}{*}{$\begin{array}{l}\text { Negotiation/Civic } \\
\text { Attitudes and Skills } \\
\text { Continuum }\end{array}$} & \multirow{2}{*}{$\begin{array}{l}\text { District } \\
\mathrm{M}\end{array}$} & Voting & \multicolumn{2}{|l|}{ Non- Voting } \\
\hline & & $\mathrm{M}$ & $\mathrm{M}$ & \\
\hline \multirow[t]{3}{*}{ Cooperation } & Attica 3.27 (3.27) & $3.27(3.22)$ & $3.28(3.25)$ & \\
\hline & Other 3.18 (3.09) & 3.28 & 3.23 & \\
\hline & Total & 3.27 & 3.25 & \\
\hline \multirow[t]{3}{*}{ Compromise/Bargaining } & Attica 3.24 (3.27) & 3.23 & 3.31 & $(3.20)$ \\
\hline & Other 3.07 (3.21) & 3.05 & 3.08 & \\
\hline & Total & 3.13 & 3.15 & \\
\hline \multirow{3}{*}{$\begin{array}{l}\text { Conflict Resolution } \\
\text { "Argument" } \\
\text { (Verbal Fight) }\end{array}$} & Attica 1.28 (1.52) & 1.18 & 1.87 & $(1.56)$ \\
\hline & Other 1.29 (1.35) & 1.30 & 1.25 & \\
\hline & Total & 1.24 & 1.42 & \\
\hline \multirow{3}{*}{$\begin{array}{l}\text { Conflict Resolution } \\
\text { "Walk Away" } \\
\text { (Neutral) }\end{array}$} & Attica 1.76 (1.76) & 1.77 & 1.75 & $(1.96)$ \\
\hline & Other $2.05(2.22)$ & 1.97 & 2.18 & \\
\hline & Total & 1.87 & 2.05 & \\
\hline \multirow{3}{*}{$\begin{array}{l}\text { Conflict Resolution } \\
\text { "Get An Adult" } \\
\text { (Constructive Action) }\end{array}$} & Attica $0.76(0.53)$ & $0.86(0.72)$ & 0.20 & $(0.52)$ \\
\hline & Other $0.64(0.47)$ & 0.58 & 0.83 & \\
\hline & Total & 0.72 & 0.65 & \\
\hline \multirow{3}{*}{$\begin{array}{l}\text { Conflict Resolution } \\
\text { "Talk It Out" } \\
\text { (Negotiation) }\end{array}$} & Attica 1.05 (1.00) & 1.08 & .91 & $(1.03)$ \\
\hline & Other 1.22 (1.13) & 1.26 & 1.15 & \\
\hline & Total & 1.17 & 1.08 & \\
\hline \multirow[t]{3}{*}{ Civic Action } & Attica 3.04 (2.88) & 3.11 & 2.65 & $(3.25)$ \\
\hline & Other 3.32 (3.39) & 3.09 & 3.85 & \\
\hline & Total & 3.10 & 3.50 & \\
\hline \multirow{3}{*}{$\begin{array}{l}\text { Interpersonal and } \\
\text { Problem-Solving Skills }\end{array}$} & Attica 3.82 (3.74) & 3.85 & 3.64 & $(3.79)$ \\
\hline & Other 3.69 (3.86) & 3.57 & 3.94 & \\
\hline & Total & 3.70 & 3.85 & \\
\hline \multirow[t]{3}{*}{ Political Awareness } & Attica 3.60 (3.61) & 3.60 & $3.623 .56)$ & \\
\hline & Other 3.75 (3.83) & 3.84 & 3.50 & \\
\hline & Total & 3.72 & 3.53 & \\
\hline \multirow[t]{3}{*}{ Social Justice } & Attica 3.57 (3.65) & 3.53 & 3.78 & $(3.72)$ \\
\hline & Other 3.67 (3.49) & 3.69 & 3.67 & \\
\hline & Total & 3.61 & 3.70 & \\
\hline \multirow[t]{3}{*}{ Civic Responsibility } & Attica 3.34 (3.34) & 3.34 & 3.34 & $(3.39)$ \\
\hline & Other $3.41(3.25)$ & 3.41 & 3.45 & \\
\hline & Total & 3.37 & 3.42 & \\
\hline \multirow{3}{*}{$\begin{array}{l}\text { Seeks Knowledge about } \\
\text { Political/Societal Issues }\end{array}$} & Attica 3.19 (3.19) & 3.19 & 3.19 & $(3.24)$ \\
\hline & Other 3.42 (3.36) & 3.48 & 3.29 & \\
\hline & Total & 3.34 & 3.26 & \\
\hline \multirow{3}{*}{$\begin{array}{l}\text { Gains in Problem-Solving } \\
\text { Skills }\end{array}$} & Attica 4.02 (3.98) & 4.04 & 3.91 & $(3.87)$ \\
\hline & Other $3.88(3.80)$ & 3.91 & 3.91 & \\
\hline & Total & 3.97 & 3.85 & \\
\hline \multirow[t]{3}{*}{ Gains in Leadership Skills } & Attica 3.34 (3.33) & 3.35 & $3.31(3.44)$ & \\
\hline & Other 3.41 (3.39) & 3.34 & 3.57 & \\
\hline & Total & 3.35 & 3.50 & \\
\hline
\end{tabular}


Table 3. Main effects and interaction effect of district origin and voting in elections on students' responses

\begin{tabular}{|c|c|c|c|c|c|c|}
\hline \multirow[t]{2}{*}{ Negotiation Continuum } & \multicolumn{2}{|c|}{ Main effect for district origin } & \multicolumn{2}{|c|}{$\begin{array}{l}\text { Main effect for } \\
\text { voting in elections }\end{array}$} & \multicolumn{2}{|c|}{$\begin{array}{l}\text { Interaction } \\
\text { effect }\end{array}$} \\
\hline & $\mathrm{F}(1,60)$ & $\mathrm{p}$ & $\mathrm{F}(1,60)$ & $\mathrm{p}$ & $\mathrm{F}(1,60)$ & $\mathrm{p}$ \\
\hline$\overline{\text { Cooperation }}$ & 0.201 & 0.656 & 0.231 & 0.795 & 0.034 & 0.855 \\
\hline $\begin{array}{l}\text { Compromise/ } \\
\text { Bargaining }\end{array}$ & $\begin{array}{c}\mathrm{F}(1,59) \\
1.093\end{array}$ & 0.301 & $F(2,59) 0.317$ & 0.730 & $\mathrm{~F}(1,59) 1.015$ & 0.903 \\
\hline $\begin{array}{l}\text { Conflict Resolution "Argument" } \\
\text { (Verbal Fight) }\end{array}$ & $\mathrm{F}(1,60) 2.789$ & 0.101 & $\mathrm{~F}(2,60) 2.417$ & 0.099 & $\mathrm{~F}(1,60) 6.173$ & 0.016 \\
\hline Conflict Resolution “Walk Away” (Neutral) & $\mathrm{F}(1,60) 0.806$ & 0.373 & $\mathrm{~F}(2,60) 0.111$ & 0.895 & $\mathrm{~F}(1,60) 0.103$ & 0.750 \\
\hline $\begin{array}{l}\text { Conflict Resolution "Get An Adult" } \\
\text { (Constructive Action) }\end{array}$ & $F(1,60) 0.417$ & 0.521 & $F(2,60) 0.682$ & 0.510 & $\mathrm{~F}(1,60) 2.792$ & 0.100 \\
\hline $\begin{array}{l}\text { Conflict Resolution "Talk It Out" } \\
\text { (Negotiation) }\end{array}$ & $\mathrm{F}(1,60) 1.765$ & 0.190 & $\mathrm{~F}(2,60) 0.520$ & 0.597 & $\mathrm{~F}(1,60) 0.024$ & 0.878 \\
\hline Civic Action & $\mathrm{F}(1,60) 5.355$ & 0.024 & $\mathrm{~F}(2,60) 0.202$ & 0.818 & $\mathrm{~F}(1,60) 5.646$ & 0.021 \\
\hline Interpersonal and Problem-Solving Skills & $\mathrm{F}(1,60) .001$ & 0.974 & $\begin{array}{c}\mathrm{F}(2,60) \\
0.156\end{array}$ & 0.856 & $\mathrm{~F}(1,60) 1.382$ & 0.245 \\
\hline Political Awareness & $\mathrm{F}(1,60) 0.038$ & 0.846 & $F(2,60) 0.282$ & 0.755 & $\begin{array}{c}\mathrm{F}(1,60) \\
0.375\end{array}$ & 0.543 \\
\hline Social Justice & $F(1,60) 0.037$ & 0.849 & $\mathrm{~F}(2,60) 1.062$ & 0.353 & $\begin{array}{c}\mathrm{F}(1,60) \\
0.857\end{array}$ & 0.359 \\
\hline Civic Responsibility & $F(1,59) 0.138$ & 0.712 & $\begin{array}{c}\mathrm{F}(2,59) \\
0.240\end{array}$ & 0.788 & $\begin{array}{c}\mathrm{F}(1,59) \\
0.008\end{array}$ & 0.931 \\
\hline $\begin{array}{l}\text { Seeks Knowledge about Political/Societal } \\
\text { Issues }\end{array}$ & $F(1,60) 0.962$ & 0.331 & $\begin{array}{c}\mathrm{F}(2,60) \\
0.130\end{array}$ & 0.879 & $\begin{array}{c}\mathrm{F}(1,60) \\
0.236\end{array}$ & 0.629 \\
\hline Gains in Problem-Solving Skills & $F(1,60) 0.105$ & 0.747 & $F(1,60) 0.105$ & 0.747 & $\begin{array}{c}\mathrm{F}(1,59) \\
0.008\end{array}$ & 0.931 \\
\hline Gains in Leadership Skills & $F(1,60) 0.181$ & 0.673 & $F(2,60) 0.070$ & 0.932 & $\begin{array}{c}\mathrm{F}(1,60) \\
0.193\end{array}$ & 0.662 \\
\hline
\end{tabular}

Notes: Attica $\mathrm{N}=26$; Other $\mathrm{N}=34$; Voting in elections $\mathrm{N}=45$; No Voting in elections $\mathrm{N}=15$; Total $\mathrm{N}=60$

Conflict resolution "walk away" (neutral): There was a non-significant main effect of district on participants" "walk away" (neutral) attitude postassessment, $\mathrm{F}(1,60)=0.806, \mathrm{p}=.373$, partial $\eta^{2}=.014$, which means that Attica and non Attica students scored similarly in their "walk away" attitude (M= 1.76 and $M=2.22$, accordingly) (estimated marginal means). There was a non-significant main effect of voting on students" "walk away" scores, $\mathrm{F}(2,60)=0.111, \mathrm{p}=.895$, partial $\eta^{2}=.004$, which means that voting and non-voting students scored similarly in their "walk away" disposition $(\mathrm{M}=1.87$ and $\mathrm{M}=$ 1.96, respectively) (estimated marginal means). There was a non-significant interaction effect between district and voting on students" "walk away" perceptions after measurement, $\mathrm{F}(1,60)=0.103$, $\mathrm{p}=.750$, partial $\eta^{2}=.002$. This indicates that Attica and non Attica both voting and non-voting counterparts were not influenced differently in the perception of "walk away" (neutral) negotiation-based behaviour
$(\mathrm{M}=1.76$ and $\mathrm{M}=2.05$ as well as $\mathrm{M}=1.87$ and $\mathrm{M}=$ 2.05 , accordingly) (normal means).

Conflict resolution "get an adult" (constructive action): There was a non-significant main effect of district on students' "get an adult" attitude, F $(1,60)=$ $0.417, p=.521$, partial $\eta^{2}=.008$, which means that Attica and non Attica students scored similarly in their "get an adult" (constructive action) perceptions $(\mathrm{M}=0.53$ and $\mathrm{M}=0.47$, respectively) (estimated marginal means). There was a non-significant main effect of voting on students" "get an adult" scores, $\mathrm{F}(2,60)=0.682, \mathrm{p}=.510$, partial $\eta^{2}=.024$, which means that voting and non-voting counterparts scored similarly in their constructive action disposition $(\mathrm{M}=$ 0.72 and $M=0.52$, respectively) (estimated marginal means). There was a non-significant interaction effect between district and voting on students" "get an adult" scores, $\mathrm{F}(1,60)=2.792$, $\mathrm{p}=.100$, partial $\eta^{2}=.048$. This indicates that Attica and non Attica both voting and non-voting peers were not affected differently in their 
perceptions of "get an adult" (constructive action) choice $(M=0.76$ and $M=0.64$ as well as $M=0.72$ and $\mathrm{M}=0.65$, accordingly) (normal means).

Conflict resolution "talk it out" (negotiation): There was a non-significant main effect of district on students" "talk it out" (negotiation) attitude, F $(1,60)=$ $1.765, \mathrm{p}=.190$, partial $\eta^{2}=.031$, which means that Attica and non Attica students scored similarly in their "talk it out" (negotiation) attitude $(\mathrm{M}=1.00$ and $\mathrm{M}=1.13$, respectively) (estimated marginal means). There was a non-significant main effect of voting on respondents' "talk it out" scores, $\mathrm{F}(2,60)=0.520$, $\mathrm{p}=.597$, partial $\eta^{2}=.019$, which means that voting and non-voting counterparts scored similarly in their "talk it out" choice $(\mathrm{M}=1.17$ and $\mathrm{M}=1.03$, respectively) (estimated marginal means). There was a nonsignificant interaction effect between district and voting on students' "talk it out" (negotiation) scores, $\mathrm{F}(1,60)=0.024, \mathrm{p}=.878$, partial $\eta^{2}=.000$. This indicates that Attica and non Attica both voting and non-voting counterparts were not affected differently in their perceptions of "talk it out" (negotiation) choice during their assessment $(\mathrm{M}=1.05$ and $\mathrm{M}=1.22$ as well as $\mathrm{M}=$ 1.17 and $\mathrm{M}=1.08$, accordingly) (normal means).

Civic Action: There was a significant main effect of district on students' willingness to be involved in community, volunteering, service learning and environmental activities in the future, $F(1,60)=$ $5.355, \mathrm{p}<.05$, partial $\eta^{2}=.089$, which means that non Attica students scored significantly higher in their disposition to be engaged in active community service, volunteering and environmental work in the future $(M=3.39)$ than their Attica peers $(M=2.88)$, respectively (estimated marginal means). There was a non-significant main effect of voting on students' willingness towards working for civic action-oriented initiatives, $\mathrm{F}(2,60)=.202, \mathrm{p}=.818$, partial $\eta^{2}=.007$, which means that voting and non-voting university students did exhibit similar scores in their perceptions of involvement with civic action projects ( $M=3.10$ and $\mathrm{M}=3.25$, accordingly) (estimated marginal means). There was a significant interaction effect between district and voting on students' civic action scores, $\mathrm{F}(1,60)=5.646, \mathrm{p}<.05$, partial $\eta^{2}=.093$. This indicates that postgraduate university students originated from Attica and non Attica region and voting and non-voting ones were influenced differently in their perceptions of actively engaged in community service and environmental activities postgaming. In particular, the perceptions of actively engaged in community and environmental volunteering reported by non Attica students $(\mathrm{M}=3.32)$ (means) were significantly higher than those indicated by their Attica peers $(M=3.04)$ (means) $\quad\left(\mathrm{x}^{2} \quad(30)=32.718, \quad \mathrm{p}<.10\right) . \quad$ However, perceptions of civic action were similar in voting $(\mathrm{M}=3.10)$ (means) and non-voting $(\mathrm{M}=3.50)$ (means) students $\left(x^{2}=(15)=19.995, p=.147\right)$. Figure 3 below illustrates the nature of the interaction effect, indicating that non Attica origin significantly affects active community and environmental engagement perceptions in non-voting students (voting ones appear unaffected) (normal means).

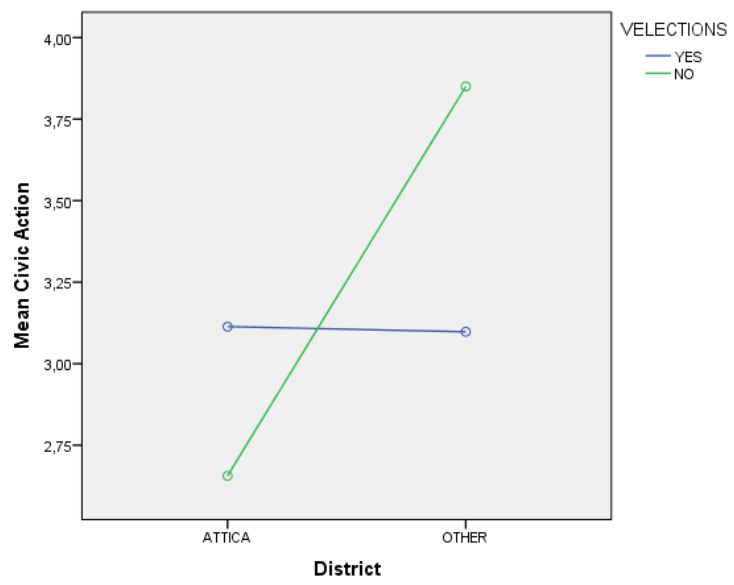

Figure 3. Graph of the interaction of district/region and voting in elections in civic action

Interpersonal and Problem-solving Skills: There was a non-significant main effect of district on students' disposition towards finding effective ways of solving problems, logical and analytical thinking and getting along with people, $\mathrm{F}(1,60)=.001, \mathrm{p}=$ .974 , partial $\eta^{2}=.000$, which means that Attica and non Attica students scored similarly in their orientation towards working cooperatively and thinking logically in assessing and solving challenges $(\mathrm{M}=3.74$ and $\mathrm{M}=3.86$, respectively) (estimated marginal means). There was a non-significant main effect of voting on students' willingness towards analytical thinking in problem-solving situations, $\mathrm{F}(2,60)=.156, \mathrm{p}=.856$, partial $\eta^{2}=.006$, which means that voting and nonvoting university students did exhibit similar scores in their perceptions of engagement in logical and analytical problem-solving conditions $(\mathrm{M}=3.71$ and $\mathrm{M}=3.79$, accordingly) (estimated marginal means). There was a non-significant interaction effect between district and voting on students' interpersonal and problem-solving scores, $\mathrm{F}(1,60)=1.382, \mathrm{p}=.245$, partial $\eta^{2}=.025$. This indicates that university students reflecting Attica and non Attica both voting and nonvoting peers were not affected differently in their perceptions of logical and analytical problem-solving ( $M=3.82$ and $M=3.69$ as well as $M=3.70$ and $M=3.85$, respectively) (normal means).

Political Awareness: There was a non-significant main effect of district on students' knowledge and disposition towards engagement in national, community and political issues (political awareness), $\mathrm{F}(1,60)=.038, \mathrm{p}=.846$, partial $\eta^{2}=.001$, which means that Attica and non Attica students scored 
similarly in their awareness of and involvement with country, community and political events $(\mathrm{M}=3.61$ and $\mathrm{M}=3.83$, respectively) (estimated marginal means). There was a non-significant main effect of voting on students' knowledge and orientation towards nationwide, community and political process challenges, $\mathrm{F}(2,60)=.282, \mathrm{p}=.755$, partial $\eta^{2}=.010$, which means that voting and non-voting university students did exhibit similar scores in their perceptions of knowledge and engagement in political process, country and community challenges $(\mathrm{M}=3.72$ and $\mathrm{M}=3.56$, accordingly) (estimated marginal means). There was a non-significant interaction effect between district and voting on students' political awareness scores, $\mathrm{F}(1,60)=.375, \mathrm{p}=.543$, partial $\eta^{2}=.007$. This indicates that university students reflecting Attica and non Attica both voting and non-voting peers were not affected differently in their knowledge and engagement in nation-wide, community and political process activities $(M=3.60$ and $M=3.75$ as well as $\mathrm{M}=3.72$ and $\mathrm{M}=3.53$, respectively) (normal means).

Social Justice: There was a non-significant main effect of district on students' orientation towards equal opportunity for individuals and community change in solving social challenges (social justice), $\mathrm{F}$ $(1,60)=.037, p=.849$, partial $\eta^{2}=.001$, which means that Attica and non Attica students scored similarly in their awareness of and disposition towards equal opportunity and public policy reforms $(\mathrm{M}=3.65$ and $\mathrm{M}=3.49$, respectively) (estimated marginal means). There was a non-significant main effect of voting on students' reflection of and orientation towards equal opportunities for individuals and public policy changes, $\mathrm{F}(2,60)=1.062, \mathrm{p}=.353$, partial $\eta^{2}=.037$, which means that voting and non-voting university students did exhibit similar scores in their social justice perceptions ( $M=3.61$ and $M=3.72$, accordingly) (estimated marginal means). There was a non-significant interaction effect between district and voting on students' social justice scores, $F(1,60)$ $=.857, \mathrm{p}=.359$, partial $\eta^{2}=.015$. This indicates that university students reflecting Attica and non Attica both voting and non-voting peers were not affected differently in their awareness of and engagement in equal opportunity for individuals and public policy change initiatives $(M=3.57$ and $M=3.67$ as well as $\mathrm{M}=3.61$ and $\mathrm{M}=3.70$, respectively) (normal means).

Civic Responsibility: There was a non-significant main effect of district on students' active concern and involvement with ensuring equal opportunity for and helping people in need, improving their neighborhood in the near future and finding a beneficial community career path, $\mathrm{F}(1,59)=.138, \mathrm{p}=.712$, partial $\eta^{2}=.003$, which means that Attica and non Attica students scored similarly in their orientation towards improving their community and work in favour of equal opportunity (social, political, vocational) for others ( $M=3.34$ and $M=3.25$, respectively) (estimated marginal means). There was a non significant main effect of voting on students' concern and engagement in community volunteering and equal opportunity for all, $\mathrm{F}(2,59)=.240, \mathrm{p}=.788$, partial $\eta^{2}=.009$ which means that voting and non-voting students scored similarly in their attitudes towards improving their community and engage in work in favour of equal opportunity for others $(\mathrm{M}=3.37$ and $\mathrm{M}=3.39$, accordingly) post-gameplay (estimated marginal means). There was a non-significant interaction effect between district and voting on students' civic responsibility scores, $\mathrm{F}(1,59)=.008, \mathrm{p}=.931$, partial $\eta^{2}=.000$. This indicates that university students reflecting Attica and non Attica both voting and nonvoting peers were not affected differently in their concern about community issues and reflection and engagement in equal opportunity for all $(\mathrm{M}=3.34$ and $\mathrm{M}=3.41$ as well as $\mathrm{M}=3.37$ and $\mathrm{M}=3.42$, respectively) (normal means).

Seeks Knowledge about Political/Societal Issues: There was a non-significant main effect of district on students' attention towards national, community and city issues and news including state government policies influencing their municipality, $F(1,60)=$ $.962, p=.331$, partial $\eta^{2}=.017$, which means that Attica and non Attica students scored similarly in their awareness of and paying attention to news and political challenges and decisions that affect their region ( $M=3.19$ and $M=3.36$, respectively) (estimated marginal means). There was a non-significant main effect of voting on students' reflection on and orientation towards equal opportunities for individuals and public policy changes, $\mathrm{F}(2,60)=.130, \mathrm{p}=.879$, partial $\eta^{2}=.005$, which means that voting and nonvoting university students did exhibit similar scores in their seek knowledge about political/societal issues perceptions $(\mathrm{M}=3.34$ and $\mathrm{M}=3.24$, accordingly) (estimated marginal means). There was a nonsignificant interaction effect between district and voting on students' seek knowledge about political/societal issues scores, $\mathrm{F}(1,60)=.236$, $\mathrm{p}=.629$, partial $\eta^{2}=.004$. This indicates that university students reflecting Attica and non Attica both voting and nonvoting peers were not affected differently in their awareness of and attention to country, community and region news and challenges including state government policies $(\mathrm{M}=3.19$ and $\mathrm{M}=3.42$ as well as $\mathrm{M}=3.34$ and $\mathrm{M}=3.26$, respectively) (normal means).

Gains in Problem-Solving Skills: There was a nonsignificant main effect of district on students' orientation towards improving creative thinking and problem-solving through individual solutions formation, $\mathrm{F}(1,60)=.105, \mathrm{p}=.747$, partial $\eta^{2}=.002$, which means that Attica and non Attica students scored similarly in their disposition towards creative and individual-focused problem-solving $(\mathrm{M}=3.98$ and 
$\mathrm{M}=3.80$, respectively) (estimated marginal means). There was a non-significant main effect of voting on students' orientation towards developing their creative thinking and own solutions for problem-solving, $\mathrm{F}(2,60)=.072, \mathrm{p}=.930$, partial $\eta^{2}=.003$, which means that voting and non-voting university students did exhibit similar scores in their modified gains in problem-solving perceptions $(M=3.97$ and $M=3.87$, accordingly) (estimated marginal means). There was a non-significant interaction effect between district and voting on students' social justice scores, $F(1,60)$ $=.005, \mathrm{p}=.942$, partial $\eta^{2}=.000$. This indicates that university students reflecting Attica and non Attica both voting and non-voting peers were not affected differently in their disposition towards improving their creative thinking and own solutions for problemsolving situations $(\mathrm{M}=4.02$ and $\mathrm{M}=3.88$ as well as $\mathrm{M}=3.97$ and $\mathrm{M}=3.85$, respectively) (normal means).

\section{Gains in Leadership Skills}

There was a non-significant main effect of district on students' orientation towards practicing leadership and decision making in working with other peers, $F$ $(1,60)=.181, p=.673$, partial $\eta^{2}=.003$, which means that Attica and non Attica students scored similarly in their disposition towards collaborative leadership and decision making exercise $(M=3.33$ and $M=3.39$, respectively) (estimated marginal means). There was a non-significant main effect of voting on students' leadership and decision making practice during peer collaboration $\mathrm{F}(2,60)=.070, \mathrm{p}=.932$, partial $\eta^{2}=.003$, which means that voting and non-voting university students did exhibit similar scores in their modified gains in leadership perceptions $(M=3.35$ and $M=3.44$, accordingly) (estimated marginal means). There was a non-significant interaction effect between district and voting on students' modified gains in leadership skills scores, $\mathrm{F}(1,60)=.193, \mathrm{p}=.662$, partial $\eta^{2}=.003$. This indicates that university students reflecting Attica and non Attica both voting and non-voting peers were not affected differently in their orientation towards exercising their leadership and decision making potential during peer interaction ( $M=3.34$ and $M=3.41$ as well as $\mathrm{M}=3.35$ and $\mathrm{M}=3.50$, respectively) (normal means).

\section{Discussion and Conclusion}

The research described in the current paper aligns with ongoing yet not exhaustive evidence indicating positive learning outcomes when serious games are used as instruction tools in relation to traditional classroom teaching [4], but explores and acquires favourable serious gaming learning outcomes within the domain of private tertiary postgraduate organizational behaviour education within negotiation/conflict management and civics/sustainability-related topics. Thus, the findings illustrated in the current work lend support to the argument that the assessed negotiation/conflict management and sustainability/environmental-related serious game seems to link postgraduate university students inter-culturally (i.e. in Greece and across different districts) with networked knowledge, dispositions and capabilities advantageous in proactively engage with negotiation/conflict resolution and civics/sustainability learning challenges, corroborating and extending previous evidence that associate civic learning serious games with favourable conflict-and-civics life attributes in relation to corresponding traditional classroom instruction [14] to private university postgraduate students registered in organizational behaviour course. The difference indicated in conflict resolution "argument" (verbal fight) disposition for non-voting Attica postgraduate students post-gameplay, tends to be in line with prior evidence indicating less integrative (problem-solving or constructive conflict resolution) negotiation continuum intention for USA undergraduate business students during negotiation/conflict resolution scenario game in classroom [22] and their peers exhibiting greater disposition of non-voting in elections [23]. Similarly, the aforementioned difference tends also to extend the aforepresented prior results to the current ones relating less integrative (i.e. problem-solving or constructive) conflict resolution strategies for postgraduate students, but overall, favourable negotiation/conflict management and civics/sustainability attributes for postgraduate students post-serious gaming. In addition, the higher active community and environmental engagement perceptions (civic action) in non Attica postgraduate students post-gameplay, are similar with prior evidence indicating higher civic engagement intentions for Taiwan students participating in a service learning project instruction [24]. However, they seem to extend the aforementioned evidence within present negotiation/conflict management and civics/sustainability postgraduate student post-serious gaming setting. Overall, the indicated findings corroborate and advance previous ones, as follows: a) in illustrating positive learning outcomes for civics/sustainability serious games with favourable civic learning-associated attributes reflecting positive civics/sustainability agency for the postgraduate organizational behaviour students assuming serious gaming role immediately post-gameplay [12], b) in revealing not only the prior evidenced region/location effect in the exercise of civic learning KASs [24], but also the region/location influence on negotiation/conflict resolution strategies previously met in undergraduate college students in North Cyprus [25] within current postgraduate student serious gaming setting alike and c) in uncovering the non-voting element in civic action postgraduate student behavioural intentions exhibited post- 
gameplay, relating civic action with voluntary community and environmental/sustainability-oriented tasks and non-voting that seem to adhere to political awareness and (or) seeking knowledge about political/societal issues attributes, respectively. Along the vein of the current findings illustrated it would be beneficial to expand, for example, the present design by a) comparing the presently assessed negotiation/conflict resolution and civics/sustainability-related serious game with other AR/VR ones in similar challenges across diverse learner cohorts and locations cross-culturally, b) exploring student in-game assessment per game level and section integrating open science, open innovation and personalization-related KASs and c) comparing the presently assessed negotiation/conflict management and civics/sustainability serious game with other classroom curricular and extra-curricular similar challenges instruction tasks/activities across different student and labour force audiences to foster networked negotiation/conflict resolution and civics/sustainability behavioural intentions, competencies and behaviours learning over the long term.

\section{Acknowledgements}

The author gratefully acknowledges the support offered by the educational institution and the time and effort that participating students spent in making this study possible.

\section{References}

[1] B. Kim, H. Park, and Y. Baek, "Not just fun, but serious strategies: using meta-cognitive strategies in game-based learning," Computers \& Education, 52, 4, 2009, pp. 800810.

[2] T. Susi, M., Johannesson, and P. Backlund, "Serious Games: An Overview", Technical Report HS- IKI -TR-07001, University of Skövde, Sweden, 2007.

[3] N. Khalili, K. Sheridan, A. Williams, K. Clark, and M. Stegman, "Students designing video games about immunology: Insights for science learning, Computers in the Schools, 28, 2011, pp. 228-240.

[4] J.J. Vogel, D.S. Vogel, J. Cannon-Bowers, C.A. Bowers, K., Muse, and M. Wright, "Computer gaming and interactive simulations for learning: A meta-analysis, $J$ Educ Comput Res, 34, 3, 2006, pp. 229-243.

[5]R. Rodela, A. Ligtenberg and R. Bosma, "Conceptualizing Serious Games as a Learning-Based Intervention in the Context of Natural Resources and Environmental Governance”, Water, 2019, 11, 245.

[6] A. Solinska-Nowak, P. Magnuszewskia, M. Curl, A. French, A. Keating, J. Mochizuki, W. Liu, R. Mechler, M. Kulakowska, and L. Jarzabek, "An overview of serious games for disaster risk management - Prospects and limitations for informing actions to arrest increasing risk", International Journal of Disaster Risk Reduction, 31, 2018, pp. 1013-1029.

[7] T. Constantinescu, O. Devisch, L. Huybrechts, "Civic participation: serious games and spatial capacity building", In Proceedings of MEDIACITY 5: Reflecting on Social Smart Cities, 1st-3rd May, Plymouth, UK, 2015, pp. 263279.

[8] M., Nefs, P. Gerretsen, D. Dooghe, I.S. Mayer, I. S.M. Meijer, "Gaming the interrelation between rail infra and station area development: Part 1-Modelling the serious game 'SprintCity' ”, In s.n. (Ed.), Next Generation Infrastructure, IEEE Society, Shenzen, 2010.

[9] T. Hirsch, "Water wars: designing a civic game about water scarcity", In Proceedings of the 8th ACM Conference on Designing Interactive Systems (DIS '10), Association for Computing Machinery, New York, NY, USA, 2010, pp. 340-343.

[10] W. Peng, M. Lee, and C. Heeter, "The effects of a serious fame on role taking and willingness to help", Journal of Communication, 60, 4, 2010, pp. 723-742.

[11] J. Raessens, "Playful identity politics: How refugee games affect the player's identity", In V. Frissen, S. Lammes, M. de Lange, J. de Mul, and J. Raessens (Eds.), Playful identities: The ludification of digital media cultures, Amsterdam: Amsterdam University Press, 2015, pp. 245260.

[12] J. Neys, F. de Grove, J. van Looy, and J. Jansz, "Poverty is not a game: Behavioral changes and long-term effects after playing PING", In Proceedings of the 62nd Annual Conference of the International Communication Association, Phoenix, May 24-28, 2012.

[13] D. Ruggiero, "The effect of playing a persuasive game on attitude and affective learning", Computers in Human Behavior, 45, 2015, pp. 213-221.

[14] K. Mitgutsch, K. 2011a. Playful learning experiences. Meaningful learning patterns in players' biographies. International Journal of Gaming and Computer-Mediated Simulations, 3, 3, 2011a, pp. 54-68.

[15] R. Glas, S. Lammes, M. de Lange, J. Raessens, and I. de Vries (Eds.), "The Playful Citizen: Civic Engagement in a Mediatized Culture", Amsterdam University Press, 2019.

[16] J. Kahne, E. Middaugh, and C. Evans, "The civic potential of video games", Cambridge, MA: The MIT Press, 2009.

[17] E. Gordon, S. Walter, and P. Suarez, P., "Engagement games: A case for designing games to facilitate real-world action", Boston, MA: EngagementLab, 2014.

[18] N. Adamo-Villani, M. Oania and S. Cooper, "Using a serious game approach to teach secure coding in introductory programming: Development and initial findings", J. Educational Technology Systems, 41, 2, 2012, pp. 107-131. 
[19] M.J. Nakkula and C.E. Nikitopoulos, "Negotiation training and interpersonal development: an exploratory study of early adolescents in Argentina", Adolescence, 36, Spring, 141, 2001, pp. 1-20.

[20] B.E. Moely, S.H. Mercer, V., Illustre, D. Miron and M. McFarland, "Psychometric properties and correlates of the civic attitudes and skills questionnaire (CASQ): A measure of students' attitudes related to service-learning", Michigan Journal of Community Service Learning, 2002, pp. 15-26.

[21] S. Arnab, K. Brown, S. Clark, I. Dunwell, T. Lim, N. Suttie, S. Louchart, M. Hendrix, S. de Freitas, "The development approach of a pedagogically-driven serious game to support Relationship and Sex Education (RSE) within a classroom setting", Computers \& Education, 69, 2013, pp. 15-30.

[22] R. Bouwman, S. van Thiel, A. van Deemen, and E. Rouwette, "Cooperation and Competition in Public-Sector. Negotiations: A Laboratory Experiment", Public Performance \& Management Review, 42, 5, 2019, pp. $1164-1185$

[23] N. Thomas, I. Bergom, I. Casellas Connors, P. Guatam, A. Gismodi, and A. Roshko, A., "Democracy Counts: A report on U.S. college and university student voting-NSLVE National Study of Learning, Voting, and Engagement", The Institute for Democracy \& Higher Education, Tufts University's Jonathan M. Tisch College of Civic Life, 2017.

[24] S.S. Cheng, "The practice of professional skills and civic engagement through service learning: A Taiwanese perspective, Higher Education, Skills and Work-Based Learning, 8, 4, 2018, pp. 422-437.

[25]S. Dinçyürek, S., "Üniversite Öğrencilerinin Kullandiklari Çatişma Çözümleme Stratejilerinin Berirlenmesi, Lefkoşa (Yayinlanmamiş Yüksek Lisans Tezi, Yakin Doğu Teknik Üniversitesi), 2003. 